\title{
Hexane isomers sorption on a functionalized metal-organic framework
}

\author{
Patricia A.P. Mendes ${ }^{a, b}$, Florence Ragon ${ }^{c}$, Alírio E. Rodrigues ${ }^{b}$, Patricia Horcajada ${ }^{c}$, Christian Serre ${ }^{c}$, \\ José A.C. Silva ${ }^{\mathrm{a}, *}$ \\ ${ }^{a}$ Escola Superior de Tecnologia e Gestão, Instituto Politécnico de Bragança, 5301-857 Bragança, Portugal

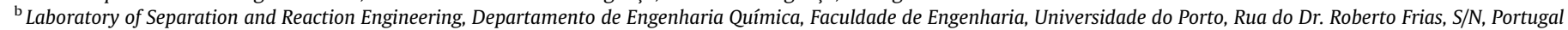 \\ ${ }^{\mathrm{c}}$ Institut Lavoisier, UMR CNRS 8180, Université de Versailles Saint-Quentin-en-Yvelines, 78035 Versailles Cedex, France
}

\section{A R T I C L E I N F O}

\section{Article history:}

Received 10 July 2012

Received in revised form 7 November 2012

Accepted 2 December 2012

Available online 20 December 2012

\section{Keywords:}

Metal-organic frameworks

Functionalization of UIO-66

Hexane isomers separation

\begin{abstract}
A B S T R A C T
A series of functionalized porous $\mathrm{Zr}$ terephthalate MOFs of the UiO-66(Zr) structure type bearing either $\mathrm{Br}, \mathrm{NH}_{2}$ or $\mathrm{NO}_{2}$ groups have been synthesized at the multi-gram scale through an atmospheric pressure solvothermal route with the final aim of investigating the influence of functionalization on the separation of hexane isomers (22DMB, 23DMB, 3MP and $n \mathrm{HEX}$ ).

The studies performed in a fixed bed adsorption column with equimolar mixtures at temperatures between 343 and $423 \mathrm{~K}$ and partial pressure up to $10 \mathrm{kPa}$ have shown that the $\mathrm{Br}, \mathrm{NO}_{2}$ and $\mathrm{NH}_{3}$ forms exhibit an uptake reaching $15 \%$, being the sorption selectivity hierarchy on the whole comparable to the bared UiO-66 solid: $22 \mathrm{DMB} \approx 23 \mathrm{DMB}>3 \mathrm{MP} \gg n \mathrm{HEX}$. The $22 \mathrm{DMB} / n$ HEX selectivity reaches approximately three at low uptake while the 22DMB/3MP selectivity of UiO-66_NO $\mathrm{N}_{2}$ is nearly constant (1.3).
\end{abstract}

(c) 2012 Elsevier Inc. All rights reserved.

\section{Introduction}

Design of specific porous structures with improved performances in adsorption separation processes and catalysis is a challenging goal of current solid state chemistry. Porous metal-organic frameworks (MOFs) are very promising candidates in both applications since they combine an important regular porosity (up to pore volumes $\sim 4 \mathrm{~cm}^{3} / \mathrm{g}$, BET surface areas up to $6500 \mathrm{~m}^{2} / \mathrm{g}$ and pore diameters $\sim 3-60 \AA$ ) with an easily tunable hybrid crystalline framework based on inorganic units (or Secondary Building Units - SBU) and organic polytopic linkers (carboxylates, phosphonates, etc.) [1]. Another interesting feature of MOFs concerns the modulation of their physico-chemical properties by incorporating active functional groups on the organic linkers [2-5], offering a highly adaptable system to solve specific separation problems $[1,6]$. Recently, the effect of the functionalization on the adsorption process, has been analyzed through the adsorption of linear alkanes on the series of highly flexible iron(III) terephthalate MIL-53(Fe)$X$ (MIL stands for Material of Institut Lavoisier; $\mathrm{X}=\mathrm{CH}_{3}, \mathrm{Cl}, \mathrm{Br}$, $\mathrm{NH}_{2}$ ) [7], or through the natural and biogas upgrading using the mesoporous aluminium amino-terephthalate MIL-101(Al) [8]. Furthermore, a quantitative structure-activity relationship (QSAR) has evidenced the impact of functionalization of the series of functionalized flexible iron(III) terephthalates MIL-88(Fe) for the adsorp-

\footnotetext{
* Corresponding author. Tel.: +351273 303125 .

E-mail address: jsilva@ipb.pt (J.A.C. Silva).
}

tion of a therapeutic molecule, paving the way for the prediction of adsorption on series of modified MOFs [9].

The conventional Total Isomerization Processes (TIP) [10] for improving the octane rating RON (Research Octane Number) of light hydrocarbons is one the first and most successful process in the application of adsorption phenomena to industrial processes. It consists in isomerizing light naphtha, mainly composed by normal paraffin's, to branched ones. Currently, the success of the process is in part due to the capacity of zeolite $5 \mathrm{~A}$ to completely separate unreacted normal from branched paraffin's. However, TIP processes suffer from the disadvantage that there are still low RON molecules in the final stream such as the mono-branched isomers of hexane. Thus, zeolite Beta has been recently used to upgrade the actual TIP processes by separating low RON mono from high RON di-branched hexane isomers [11,12], improving the final stream RON number from 86 to 92. Porous MOFs have been also proposed to improve the separation of hexane isomers and thus increase the RON number. Thus, we have recently reported the use of the highly stable $\left(\mathrm{T} \sim 350-400{ }^{\circ} \mathrm{C}\right.$ or $\left.\mathrm{P} \sim 10,000 \mathrm{~kg} / \mathrm{cm}^{2}\right)$ porous cubic zirconium terephthalate $\mathrm{UiO}-66$ (UiO for University of Oslo; $\left.\mathrm{Zr}_{6} \mathrm{O}_{4}(\mathrm{OH})_{4}\left(\mathrm{C}_{6} \mathrm{H}_{4}\left(\mathrm{CO}_{2}\right)_{2}\right)_{6} \cdot n \mathrm{H}_{2} \mathrm{O}\right)$ [13] for the separation of hexane isomers mixtures ( $n$-hexane (nHEX), 3-methylpentane (3MP), 2,3-dimethylbutane (23DMB), 2,2dimethylbutane (22DMB)). Remarkably, UiO-66 which possesses an important porosity $\left(\mathrm{S}_{\mathrm{BET}}>1100 \mathrm{~m}^{2} / \mathrm{g}\right)$ with tetrahedral $(\sim 8 \AA)$ and octahedral cavities ( $\sim 11 \AA$ ) accessible by microporous triangular windows $(5-7 \AA)$, exhibited an opposite sorption hierarchy (22DMB $>23 \mathrm{DMB}>$ $3 \mathrm{MP}>n \mathrm{HEX})$ to the one observed in conventional adsorbents 
[14], with selectivity values reaching four for the ratio 22DMB/ $n$ HEX. This reverse shape selectivity might be attributed to the rotational freedom of the molecules within the small cages [14].

Hexane isomers adsorption might be modified by adjusting the dimensions of the windows through the introduction of different functional groups in substitution to one proton of the terephthalate linker, as already reported for the $\mathrm{CO}_{2}$ adsorption over gases such as $\mathrm{CH}_{4}$ and $\mathrm{N}_{2}$ [15]. This selectivity increase could be related with the significant reduction of the ability to rotate of the aromatic ring upon the grafting of a $-\mathrm{NH}_{2}$ group [16]. Therefore, we report here the effect of the functionalization of the UiO-66 architecture on the separation of hexane isomers by adsorption. To that purpose, three porous UiO-66 materials built up from terephthalate linkers bearing different functional groups $\left(-\mathrm{Br},-\mathrm{NH}_{2},-\mathrm{NO}_{2}\right)$ were synthesized at the multi-gram scale under atmospheric pressure. These functionalized UiO-66 solids were fully characterized by X-ray powder diffraction (XRPD), infrared spectroscopy (IR), thermogravimetric analysis (TGA), diffusion light scattering (DLS) and nitrogen adsorption measurement. The potential of separation of the hexane isomers has been then assessed on the UiO-66(_Br, _ $\mathrm{NH}_{2}, \mathrm{NO}_{2}$ ) materials by performing several screening studies in a breakthrough apparatus exploiting the effect of temperature and partial pressure.

\section{Experimental section}

\subsection{Synthesis and characterization of UiO-66 solids}

\subsubsection{Zirconium 2-bromoterephthalate or UiO-66_Br \\ $\left(\mathrm{Zr}_{6} \mathrm{O}_{4}(\mathrm{OH})_{4}\left(\mathrm{C}_{6} \mathrm{H}_{3} \mathrm{Br}\left(\mathrm{CO}_{2}\right)_{2}\right)_{6} \cdot \mathrm{nH}_{2} \mathrm{O}\right)$}

$8.15 \mathrm{~g}$ of zirconium oxychloride octahydrate, $\mathrm{ZrOCl}_{2} \cdot 8 \mathrm{H}_{2} \mathrm{O}$ (25.29 mmol; Alfa Aesar, 98\%) and $4 \mathrm{~mL}$ of $12 \mathrm{M}$ hydrochloric acid $(\mathrm{HCl} ; 48 \mathrm{mmol})$ were added to an initial solution of $6.10 \mathrm{~g}$ of 2-bromoterephthalic acid (Br-BDC; $24.89 \mathrm{mmol}$; Aldrich, 99\%) in $63 \mathrm{~mL}$ of $\mathrm{N}, \mathrm{N}$-dimethylformamide (DMF; $814.11 \mathrm{mmol}$; Carlo Erba, 99.7\%). The final solution was stirred for $15 \mathrm{~min}$ and heated under reflux was for $24 \mathrm{~h}$. The final product was filtered at room temperature resulting in a white viscous material. The amount of obtained solid was $7.90 \mathrm{~g}$.

The previously obtained solid was first washed overnight with $500 \mathrm{~mL}$ of DMF under vigorous in order to remove the free remaining 2-bromoterephthalic acid (this procedure was repeated five times). A second cleaning using $500 \mathrm{~mL}$ of methanol (MeOH, Aldrich, 99\%) was necessary to replace the DMF within the pores (this step was repeated three times). Between each washing step, efficacy of the washing of the sample was checked by infra-red analyses. The weight of the final UiO-66_Br solid was $6.50 \mathrm{~g}$ which corresponds to a yield of $92 \%$.

\subsubsection{Zirconium 2-aminoterephthalate or UiO-66- \\ $\mathrm{NH}_{2}\left(\mathrm{Zr}_{6} \mathrm{O}_{4}(\mathrm{OH})_{4}\left(\mathrm{C}_{6} \mathrm{H}_{3} \mathrm{NH}_{2}\left(\mathrm{CO}_{2}\right)_{2}\right)_{6} \cdot \mathrm{nH}_{2} \mathrm{O}\right)$}

After the dissolution of $7.24 \mathrm{~g}$ of 2-aminoterephthalic acid $\left(\mathrm{NH}_{2}-\mathrm{BDC} ; 40.2 \mathrm{mmol}\right.$; Alfa Aesar, $\left.98 \%\right)$ in $100 \mathrm{~mL}$ of $\mathrm{DMF}$ (1.29 mol; Carlo Erba, 99.7\%), $12.9 \mathrm{~g}$ of $\mathrm{ZrOCl}_{2} \cdot 8 \mathrm{H}_{2} \mathrm{O}$ (40 mmol; Alfa Aesar, $98 \%)$ and $6.4 \mathrm{~mL}$ of $\mathrm{HCl} 12 \mathrm{M}(76 \mathrm{mmol})$ were added. The mixture was placed in a round bottom flask under mechanical stirring and reflux for $24 \mathrm{~h}$. Thereafter, the final product was filtered resulting in a yellow viscous material. The amount of obtained solid was $11.6 \mathrm{~g}$.

Similar washing procedure to the previous one used to UiO$66 \_\mathrm{Br}$ was employed to remove free non-reacted ligand and DMF. Thus, two washes with $500 \mathrm{~mL}$ of DMF followed by three washes with $\mathrm{MeOH}$ were required to totally wash the sample. The weight of the final UiO-66_NH $\mathrm{NH}_{2}$ solid was $10.2 \mathrm{~g}$, which corresponds to a yield of $73 \%$.

\subsubsection{Zirconium 2-aminoterephthalate or UiO-66_ $\mathrm{NO}_{2}$ \\ $\left(\mathrm{Zr}_{6} \mathrm{O}_{4}(\mathrm{OH})_{4}\left(\mathrm{C}_{6} \mathrm{H}_{3} \mathrm{NO}_{2}\left(\mathrm{CO}_{2}\right)_{2}\right)_{6} \cdot \mathrm{nH}_{2} \mathrm{O}\right)$}

After the complete dissolution of $1.69 \mathrm{~g}$ of 2-nitroterephthalic acid ( $\mathrm{NO}_{2}$ BDC; $8 \mathrm{mmol}$; Aldrich, $\left.99 \%\right)$ in $8.67 \mathrm{~mL}$ of DMF (112 mmol; Carlo Erba, 99.7\%), $1.69 \mathrm{~g}$ of $\mathrm{ZrOCl}_{2} \cdot 8 \mathrm{H}_{2} \mathrm{O}$ (8 mmol; Alfa Aesar, $98 \%)$ and $1.33 \mathrm{~mL}$ of $\mathrm{HCl} 12 \mathrm{M}(15.96 \mathrm{mmol})$. The mixture was stirred in a round bottom under reflux for $24 \mathrm{~h}$. After filtration, $2.50 \mathrm{~g}$ of material were obtained.

Similar washing processes were applied to this solid. In this case three washes with $500 \mathrm{~mL}$ of DMF and three washes with $500 \mathrm{~mL}$ of $\mathrm{MeOH}$ were needed to completely wash the sample. The amount of activated UiO-66_NO $\mathrm{NO}_{2}$ was $1.50 \mathrm{~g}$, which corresponds to a yield of $58 \%$.

XRPD patterns of functionalized UiO-66 solids showed the characteristic Bragg peaks of the rigid UiO-66 solid (Fig. 1). Furthermore, the purity, porosity and particle size of all samples were fully characterized by IR, TGA, DLS and nitrogen adsorption measurement (see Supporting information $A 1, A 2$ and $A 3$ for the UiO-66_Br, UiO-66_NO ${ }_{2}$ and UiO-66_NH 2 , respectively).

\subsection{Adsorption equilibrium apparatus}

The experimental set-up used for the screening studies is reported in detail elsewhere [17]. Briefly, it consists of three main sections. The first is a gas preparation section including a syringe pump used to introduce the adsorbable species in the carrier gas. The second section is the oven where the fixed bed column $\left(L=100 \mathrm{~mm}, d_{\mathrm{i}}=4.6 \mathrm{~mm}\right)$ is placed. Finally, a third section that consists of a 12 loop sample collector (SC) directly attached to a gas chromatograph system where the samples are analyzed.

In a typical experiment the hydrocarbons (purchased from $\mathrm{Al}$ drich) are introduced continuously in a helium stream of minimum purity 99.999\% (ALPHAGAZ 1, Air Liquide, France). A FID detector measures the concentration history of the fixed bed and when necessary samples are trapped in the SC. When the experiment finishes the composition of the collected samples is evaluated by chromatography using a $2 \mathrm{~m}$ long, $2 \mathrm{~mm}$ ID, Chromosorb W-HP packed column 5\% Bentone 34, 5\% SP-1200 on Chromosorb 100/ 120 mesh (Restek Corporation, Bellefonte, PA, USA). Before starting a series of experiments, the functionalized UiO-66 samples were activated in its powdered form by placing it under vacuum at $473 \mathrm{~K}$ during $15 \mathrm{~h}$. Thereafter the beds were loaded without sieving and plus activated in an inert flow of helium for $12 \mathrm{~h}$.

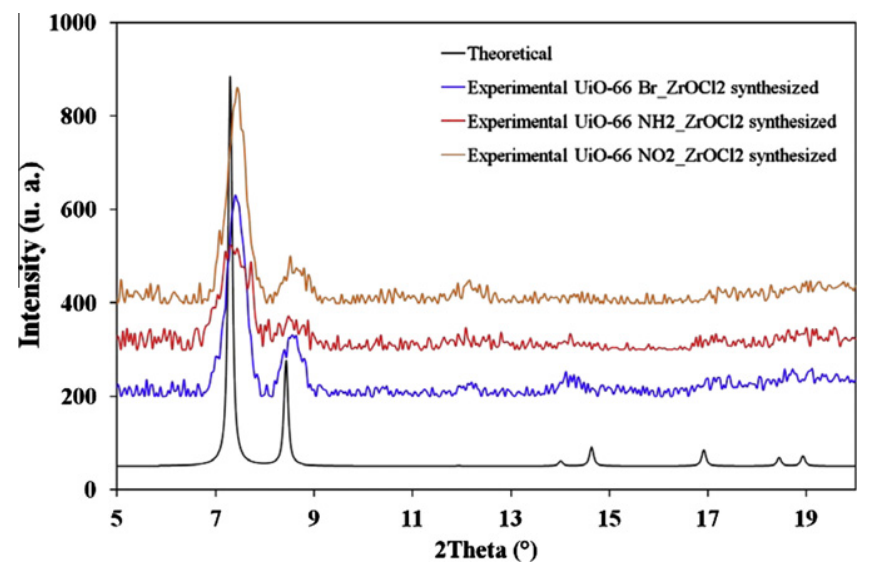

Fig. 1. XRPD of the reported theoretical UiO-66 pattern (black), the UiO-66_NO $\mathrm{NO}_{2}$ (orange), UiO-66_ $\mathrm{NH}_{2}$ (red), UiO-66_Br (blue) using a Siemens diffractometer D5000 ( $\mathrm{Cu} \mathrm{K} \alpha 1$ radiation $\lambda=1.54056 \AA$ ). (For interpretation of the references to colour in this figure legend, the reader is referred to the web version of this article.) 

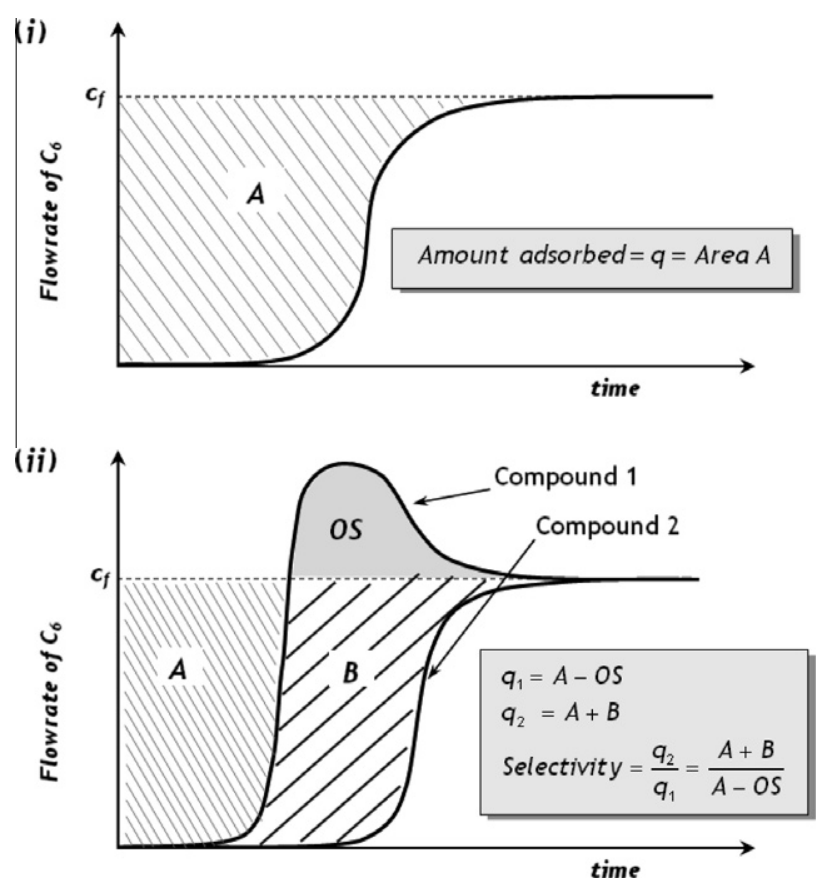

Fig. 2. Schematic diagram showing the method used to calculate the amount adsorbed from breakthrough curves: (i) single and (ii) binary-component experiment.

The equilibrium loading in each experiment is obtained by integration of the adsorption curves measured in terms of mass flux as a function of time. An example of the procedure is exemplified in Fig. 2(i) for a single component experiment and in Fig. 2(ii) for a binary one. In the single component experiment the number of moles retained in the bed is simply Area A (see Fig. 1(i)). For a binary experiment (Fig. 2(ii)) the number of moles of compound 1 retained in the bed is equal to the Area $A$ minus the roll-up area OS. For the compound 2, the number of moles retained in the bed is equal to Area A plus Area B. The amount adsorbed of each compound is then calculated by the following relations:

$q_{1}=$ Area $A-$ Area $O S$

$q_{2}=$ Area $A+$ Area $B$

In the case of an equimolar mixture the selectivity, $S$, is given by the quotient between the amounts adsorbed of the two species as follows:

$S=\frac{q_{2}}{q_{1}}=\frac{\text { Area } A+\text { Area } B}{\text { Area } A-\text { Area } O S}$

\section{Results and discussion}

Functionalization of the linker is an easy way to modulate the physico-chemical properties of the MOF and so, its adsorptive properties. Functionalization of UiO-66 solid has previously been reported either using direct synthesis from linkers bearing functional groups (in situ) [4] or by post synthetic modification [18]. The in situ route leads to more homogeneous and entirely functionalized MOFs. Thus, Kandiah et al. has reported the direct synthesis of UiO-66 solids using terephthalate derivatives bearing $\mathrm{NH}_{2},-\mathrm{NO}_{2}$ and $-\mathrm{Br}$ groups and $\mathrm{ZrCl}_{4}$ as metal precursor through solvothermal method [4]. Fig. 3 gives the schematic illustration of the three-dimensional arrangement of one octahedral cage surrounded by one tetrahedral cage and connected through the narrow triangular windows in the UiO-66 solids. The possible

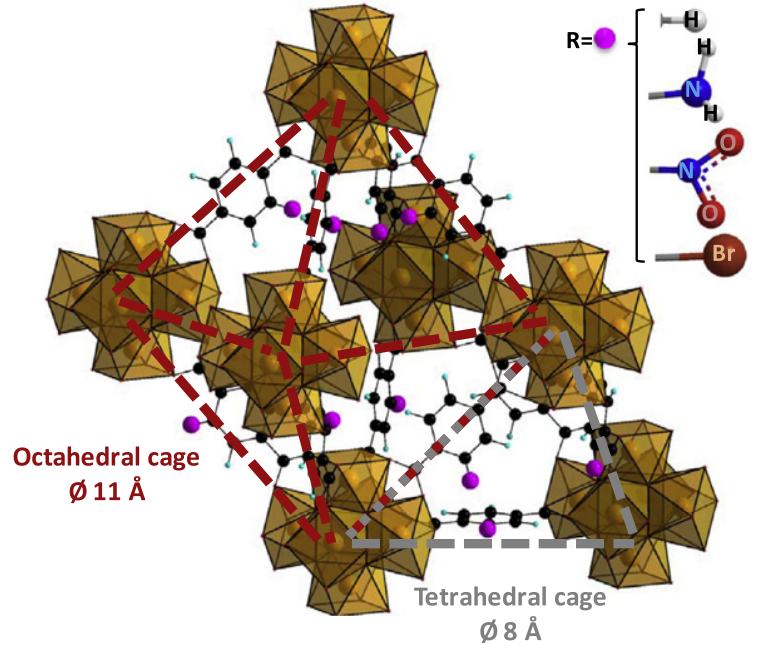

Fig. 3. Schematic illustration of one octahedral (red dotted line) and one tetrahedral cage (grew dotted line) of the modified UiO-66 structure. The purple sphere represents the possible position of the grafted functional group on the benzene ring. (For interpretation of the references to colour in this figure legend, the reader is referred to the web version of this article.)

positions of the grafted functional groups are schematically represented, clearly showing that the accessible size of the windows might decrease with the presence of the functional group. In the present work, we report a new synthesis route of the UiO-66_Br, $\mathrm{NH}_{2}$ and $\mathrm{NO}_{2}$ using a cheaper metal precusor $\left(\mathrm{ZrOCl}_{2} \cdot 8 \mathrm{H}_{2} \mathrm{O}\right)$ combined to an atmospheric pressure synthesis route (see Supporting information). This method, not only is safier avoiding the use of high pressures, but also allows the reproducible preparation of larger amounts of UiO-66 products at the multi-gram scale (up to $10.2 \mathrm{~g}$ for UiO-66_NH $\mathrm{NH}_{2}$ ) associated with important yields (up to $92 \%$ for UiO-66_Br). Crystallinity of the functionalized UiO-66 solids synthesized via $\mathrm{ZrOCl}_{2}$ at atmospheric pressure was however lower than that of the materials obtained from $\mathrm{ZrCl}_{4}$ solvothermal method, in agreement with a smaller particle size (see Supporting information). This was confirmed by DLS measurements, resulting in particles sizes, for the $\mathrm{ZrCl}_{4}$ solvothermal method, around 900, 910 and $1400 \mathrm{~nm}$ for the UiO-66_NO $\mathrm{NO}_{2}, \mathrm{NH}_{2}$ and _Br, respectively, against 760,630 and $850 \mathrm{~nm}$ for the atmospheric pressure route, respectively. However, no significant differences in terms of microporosity were observed between both methods, except for the UiO-66_NH $\mathrm{NH}_{2}$ synthesized from $\mathrm{ZrCl}_{4}$ solvothermal method, which exhibited a higher surface area (930 vs. $650 \mathrm{~m}^{2} / \mathrm{g}$ ) with however similar pore volume $\left(0.37 \mathrm{~cm}^{3} / \mathrm{g}\right)$.

\subsection{Screening studies of hexane isomers in UiO-66_Br}

The studies were performed with equimolar mixtures of $n \mathrm{HEX}$, $3 \mathrm{MP}, 23 \mathrm{DMB}$ and 22DMB at two different temperatures (343 and $423 \mathrm{~K})$ and three partial pressures: low $(0.3 \mathrm{kPa})$, moderate $(0.8 \mathrm{kPa})$ and high pressure $(10 \mathrm{kPa})$. The amount of sample used was $391 \mathrm{mg}$. The experimental conditions and adsorbed amounts of the hexane isomers in each run (calculated from the breakthrough curves [17]) are reported in Table 1.The total adsorbed amount range from $4.4 \%$ at $423 \mathrm{~K}$ and $0.3 \mathrm{kPa}$ to $15.2 \%$ at $343 \mathrm{~K}$ and $10 \mathrm{kPa}$, which can be considered significant values when compared to zeolites where the total temperature independent maximum loading reach 9\% [17] in pellets of zeolite Beta with an amount of binder ranging from $20 \%$ to $30 \%$ in weight. The selectivities measured by the ratio of the adsorbed amount of the isomers (relatively to the less adsorbed component $n \mathrm{HEX}$ ) are given in Table 2 . The higher value is observed for the experiment performed at 
Table 1

Experimental conditions and adsorbed amounts of hexane isomers in MOF UiO-66_Br.

\begin{tabular}{|c|c|c|c|c|c|c|c|c|c|}
\hline \multirow[t]{2}{*}{ Run } & \multirow[t]{2}{*}{$T(\mathrm{~K})$} & \multirow[t]{2}{*}{ Helium flow rate $(\mathrm{mL} / \mathrm{min})$} & \multirow[t]{2}{*}{ Mixture pressure (kPa) } & \multirow[t]{2}{*}{$m_{\mathrm{MOF}}(\mathrm{mg})$} & \multicolumn{4}{|c|}{ Partial loading (g/100 gads) } & \multirow[t]{2}{*}{ Total loading ( $\mathrm{g} / 100 \mathrm{~g}_{\mathrm{ads}}$ ) } \\
\hline & & & & & 22DMB & 23DMB & $3 \mathrm{MP}$ & $n \mathrm{HEX}$ & \\
\hline Br_a1 & 343 & 40 & 0.30 & & 2.6 & 2.8 & 2.3 & 1.7 & 9.4 \\
\hline Br_b1 & 423 & & & & 1.3 & 1.3 & 1.3 & 0.5 & 4.4 \\
\hline Br_a2 & 343 & 30 & 0.8 & 391 & 3.3 & 3.5 & 3.2 & 2.6 & 12.6 \\
\hline Br_b2 & 423 & & & & 2.8 & 2.8 & 2.7 & 2.3 & 10.6 \\
\hline Br_a3 & 343 & 15 & 10 & & 3.5 & 4.1 & 3.9 & 3.7 & 15.2 \\
\hline Br_b3 & 423 & & & & 3.5 & 3.7 & 3.2 & 3.1 & 13.5 \\
\hline
\end{tabular}

Table 2

Selectivities of hexane isomers in MOF UiO-66_Br.

\begin{tabular}{|c|c|c|c|c|c|}
\hline \multirow[t]{2}{*}{ Run } & \multirow[t]{2}{*}{$T(\mathrm{~K})$} & \multirow[t]{2}{*}{ Mixture pressure (kPa) } & \multicolumn{3}{|l|}{ Selectivity's } \\
\hline & & & 22DMB/nHEX & 23DMB/nHEX & $3 \mathrm{MP} / n \mathrm{HEX}$ \\
\hline Br_a1 & 343 & 0.3 & 1.4 & 1.5 & 1.3 \\
\hline Br_b1 & 423 & & 2.9 & 2.9 & 2.9 \\
\hline $\mathrm{Br} \_\mathrm{a} 2$ & 343 & 0.8 & 1.3 & 1.4 & 1.2 \\
\hline Br_b2 & 423 & & 1.3 & 1.3 & 1.2 \\
\hline Br_a3 & 343 & 10 & 0.96 & 1.1 & 1.1 \\
\hline Br_b3 & 423 & & 1.0 & 1.2 & 1.1 \\
\hline
\end{tabular}

$423 \mathrm{~K}$ and $0.3 \mathrm{kPa}$, and achieves almost 2.9 for the ratio 22DMB/ $n$ HEX. Moreover, the total adsorbed amount at these conditions is the lowest (4.4\%) (see Table 1). This means that low uptake improves the host-guest interactions, which could play a role in the selectivity increasing between $n \mathrm{HEX}$ and the rest of isomers. This effect can be rationalized if we regard to the porous phase as a surface containing heterogeneous active sites where the guest molecules can adsorb. The surface can also be energetic heterogeneous. When we have a mixture in the gas phase there will be competition for sorption in the active sites being logic to think that at low partial pressure the highest energetic sites are first occupied with the preferential molecules. This effect results in a higher selectivity. As the loading increases there will be less high energetic sites to occupy resulting in a lower selectivity. This effect has also been observed by Couck et al. [19] in the separation of $\mathrm{CO}_{2}$ from light gases in a functionalized $\mathrm{NH}_{2}$-MIL-53(Al) metal-organic framework.

The sorption hierarchy is in most runs: $22 \mathrm{DMB} \approx 23 \mathrm{DMB}>$ $3 \mathrm{MP} \gg n \mathrm{HEX}$. This unusual reverse shape selectivity ( $n \mathrm{HEX}$ is the less adsorbed component), previously reported by Barcia et al. for the bared UiO-66 solid [14], is once again observed in all runs, evidencing that the functionalization of the ligand does not impact the sorption hierarchy of the hexane isomers. As explained the reverse shape selectivity seems to be related with the linear long nature of $n \mathrm{HEX}(1.03 \times 0.49 \mathrm{~nm})$, which might be too long to be accommodated into the small tetrahedral cages ( $\sim 8 \AA$; Fig. 3 ). Accordingly, the adsorbed amounts of $n$ HEX are lower than for the other isomers since the tetrahedral cavities of the framework would be inaccessible for $n$ HEX molecules. Although the selectivity values of the branched paraffins related to $n \mathrm{HEX}$ reach 2.9 (Run_Br_b1), the major drawback for the UiO-66_Br solid is its lower selectivity between the mono and di-branched paraffins $(\sim 1.1)$ which is, in addition, practically independent of the uptake. Further considerations dealing with the influence of the uptake on the selectivities of hexane isomers in the different solids are given in Section 3.4.

Fig. 4 shows the breakthrough curves of the hexane isomers for all runs. $n \mathrm{HEX}$ is clearly the first component to break the column followed by 3MP, 22DMB and 23DMB, respectively. The roll-up for $n \mathrm{HEX}$ is very significant reaching a value around 3.5 for Run_Br_1a (Fig. 4a1), suggesting a strong sorption competition between $n$ HEX and the other hexane isomers on the framework.

\subsection{Screening studies of hexane isomers on UiO-66_NO $\mathrm{NO}_{2}$}

In this set of experiments the fixed bed column was packed with $395 \mathrm{mg}$ of UiO-66_NO $\mathrm{NO}_{2}$ material. The studies covered two temperatures ( 343 and $423 \mathrm{~K}$ ) and three partial pressures $(0.3$, 0.8 and $10 \mathrm{kPa}$ ). The experimental conditions and adsorbed amounts in each run are given in Table 3. The adsorbed amounts are very similar to the ones obtained when using UiO-66_Br as adsorbent (Table 1), with an uptake reaching 15.1\% (Run_NO $\mathrm{NO}_{2} \mathrm{a} 3$ ). The sorption hierarchy on most of the runs is once again: $22 \mathrm{DMB} \approx 23 \mathrm{DMB}>3 \mathrm{MP}>n \mathrm{HEX}$.

Table 4 gives the measured selectivity related to $n$ HEX. Contrary to UiO-66_Br, at low uptake (Runs_NO $\mathrm{N}_{2}$ b1, b2, a2) the UiO$66 \_\mathrm{NO}_{2}$ solid shows a certain degree of separation between 3MP and the di-branched isomers which is clearly an advantage.

Fig. 5 shows the breakthrough curves for all the experiments performed. Once more, a significant roll-up of $n \mathrm{HEX}$ is observed in most of the runs (nearly 5 for Run_NO $\mathrm{N}_{2}$ a1). For practical purposes UiO-66_NO $\mathrm{NO}_{2}$ at $343 \mathrm{~K}$ and $0.8 \mathrm{kPa}$ (Run_NO $\mathrm{NO}_{2}$ a2, Fig. $5 \mathrm{a} 2$ ) is the most promising system since the separation between $n \mathrm{HEX}$ and $3 \mathrm{MP}$ from the di-branched isomers 23DMB and 22DMB is evidenced.

\subsection{Screening studies of hexane isomers on UiO-66_N $\mathrm{NH}_{2}$}

Here, the column was packed with $452 \mathrm{mg}$ of UiO-66_NH $\mathrm{NH}_{2}$. The experiments covered two temperatures ( 343 and $423 \mathrm{~K}$ ) and two partial pressures: 0.3 and $6 \mathrm{kPa}$. The experimental conditions and adsorbed amounts of each run are summarized in Table 5 . The adsorbed amount of the components in each run is very similar, except at low temperature ( $343 \mathrm{~K}$ ) and high partial-pressure (6 $\mathrm{kPa}$; Run_NH $\mathrm{NH}_{2} \mathrm{a} 2$ ) where the adsorbed amount of $22 \mathrm{DMB}$ is $2 \%$, a value considerably smaller than for the other isomers (3.5\%). Table 6 discloses the selectivities for each run measured again relatively to $n$ HEX. A reverse selectivity for 22DMB is observed in $\mathrm{Run} \_\mathrm{NH}_{2}$ a 2 with a value around 0.6. For industrial purposes the separation performance obtained with UiO-66_NH $\mathrm{NH}_{2}$ at $343 \mathrm{~K}$ and $6 \mathrm{kPa}$ (Run_NH $\mathrm{N}_{2} \mathrm{a} 2$ ) is the most convenient in order to separate 22DMB (high RON) from the other low RON isomers. Breakthrough curves (Fig. 6) show a small degree of separation between the isomers, except for Run_NH $\mathrm{NH}_{2} \mathrm{a} 2$ (343 $\mathrm{K}$ and $6 \mathrm{kPa}$ ) which lead to an uptake of $12 \%$. 

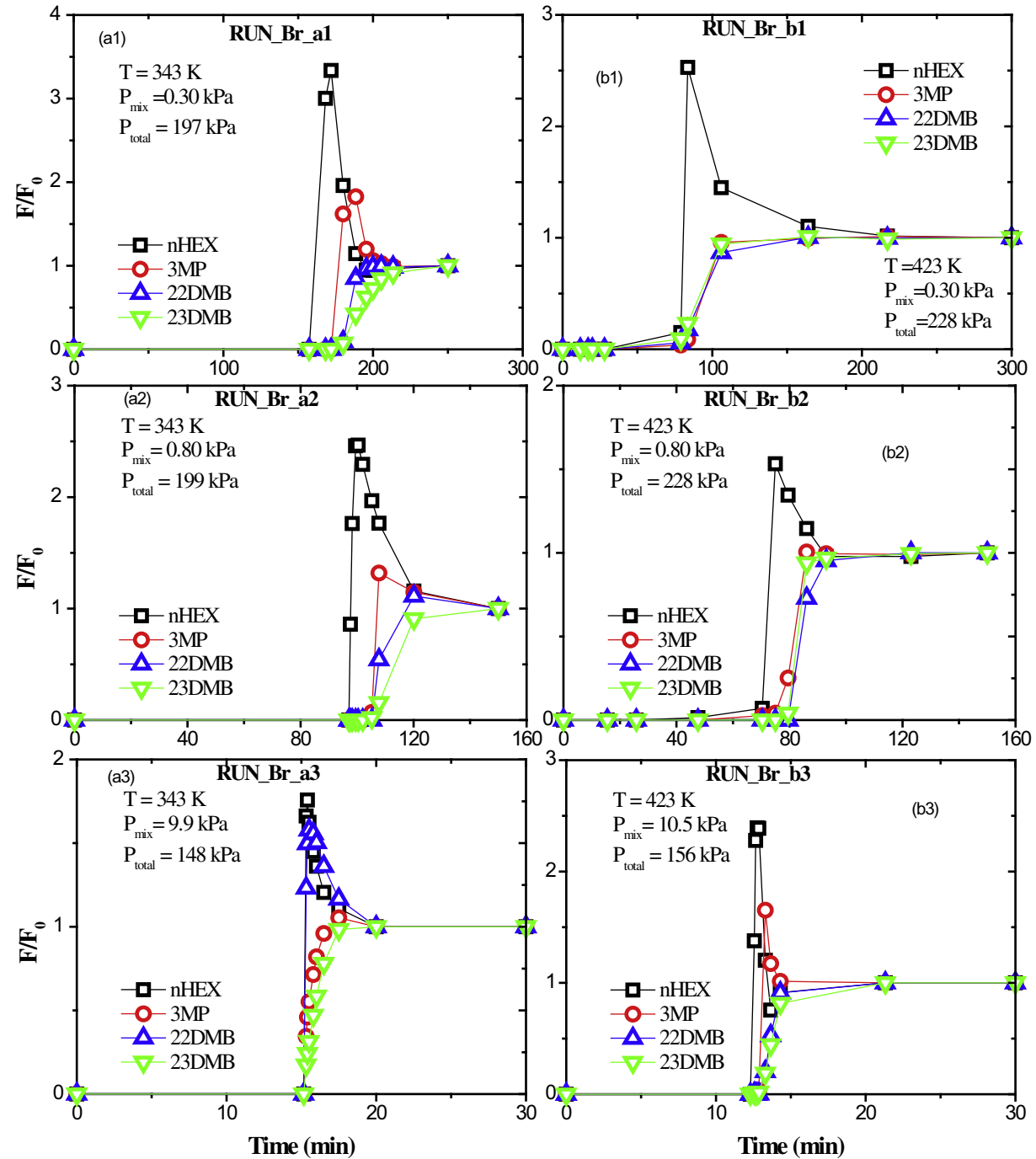

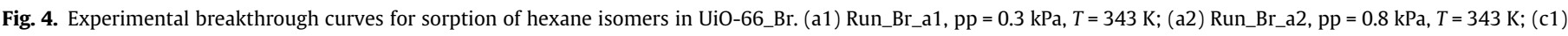

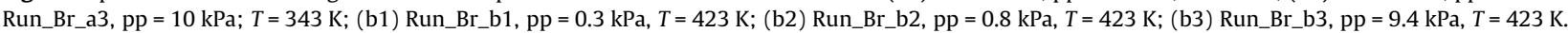

Table 3

Experimental conditions and amount adsorbed of hexane isomers in MOF UiO-66_NO ${ }_{2}$.

\begin{tabular}{|c|c|c|c|c|c|c|c|c|c|}
\hline \multirow[t]{2}{*}{ Run } & \multirow[t]{2}{*}{$T(\mathrm{~K})$} & \multirow[t]{2}{*}{ Helium flow rate $(\mathrm{mL} / \mathrm{min})$} & \multirow[t]{2}{*}{ Mixture pressure $(\mathrm{kPa})$} & \multirow[t]{2}{*}{$m_{\mathrm{MOF}}(\mathrm{mg})$} & \multicolumn{4}{|c|}{ Partial loading (g/100 gads) } & \multirow[t]{2}{*}{ Total loading (g/100 gads) } \\
\hline & & & & & 22DMB & 23DMB & $3 \mathrm{MP}$ & $n \mathrm{HEX}$ & \\
\hline $\mathrm{NO}_{2 \_\mathrm{a} 1}$ & 343 & 40 & 0.3 & 395 & 2.2 & 2.3 & 2.1 & 1.2 & 7.8 \\
\hline $\mathrm{NO}_{2 \_} \mathrm{b} 1$ & 423 & & & & 1.8 & 1.7 & 1.6 & 1.3 & 6.4 \\
\hline $\mathrm{NO}_{2 \_\mathrm{a} 2}$ & 343 & 30 & 0.8 & & 2.8 & 2.8 & 2.4 & 1.5 & 9.5 \\
\hline $\mathrm{NO}_{2-} \mathrm{b} 2$ & 423 & & & & 2.6 & 2.4 & 2.1 & 1.6 & 7.0 \\
\hline $\mathrm{NO}_{2 \_} \mathrm{a} 3$ & 343 & 15 & 10 & & 3.8 & 4.0 & 3.8 & 3.5 & 15.1 \\
\hline $\mathrm{NO}_{2 \_} \mathrm{b} 3$ & 423 & & & & 4.0 & 4.0 & 3.8 & 3.3 & 15.1 \\
\hline
\end{tabular}

Table 4

Selectivities of hexane isomers in MOF UiO-66_NO $\mathrm{NO}_{2}$.

\begin{tabular}{|c|c|c|c|c|c|}
\hline \multirow[t]{2}{*}{ Run } & \multirow[t]{2}{*}{$T(\mathrm{~K})$} & \multirow[t]{2}{*}{ Mixture pressure (kPa) } & \multicolumn{3}{|l|}{ Selectivity's } \\
\hline & & & 22DMB/nHEX & 23DMB/nHEX & $3 \mathrm{MP} / n \mathrm{HEX}$ \\
\hline $\mathrm{NO}_{2 \_\mathrm{a} 1}$ & 343 & 0.3 & 1.8 & 1.9 & 1.8 \\
\hline $\mathrm{NO}_{2-} \mathrm{b} 1$ & 423 & & 1.3 & 1.3 & 1.1 \\
\hline $\mathrm{NO}_{2 \_} \mathrm{a} 2$ & 343 & 0.8 & 1.8 & 1.8 & 1.5 \\
\hline $\mathrm{NO}_{2} \_\mathrm{b} 2$ & 423 & & 1.6 & 1.5 & 1.3 \\
\hline $\mathrm{NO}_{2 \_} \mathrm{a} 3$ & 343 & 10 & 1.1 & 1.2 & 1.1 \\
\hline $\mathrm{NO}_{2}$ b3 & 423 & & 1.2 & 1.2 & 1.2 \\
\hline
\end{tabular}



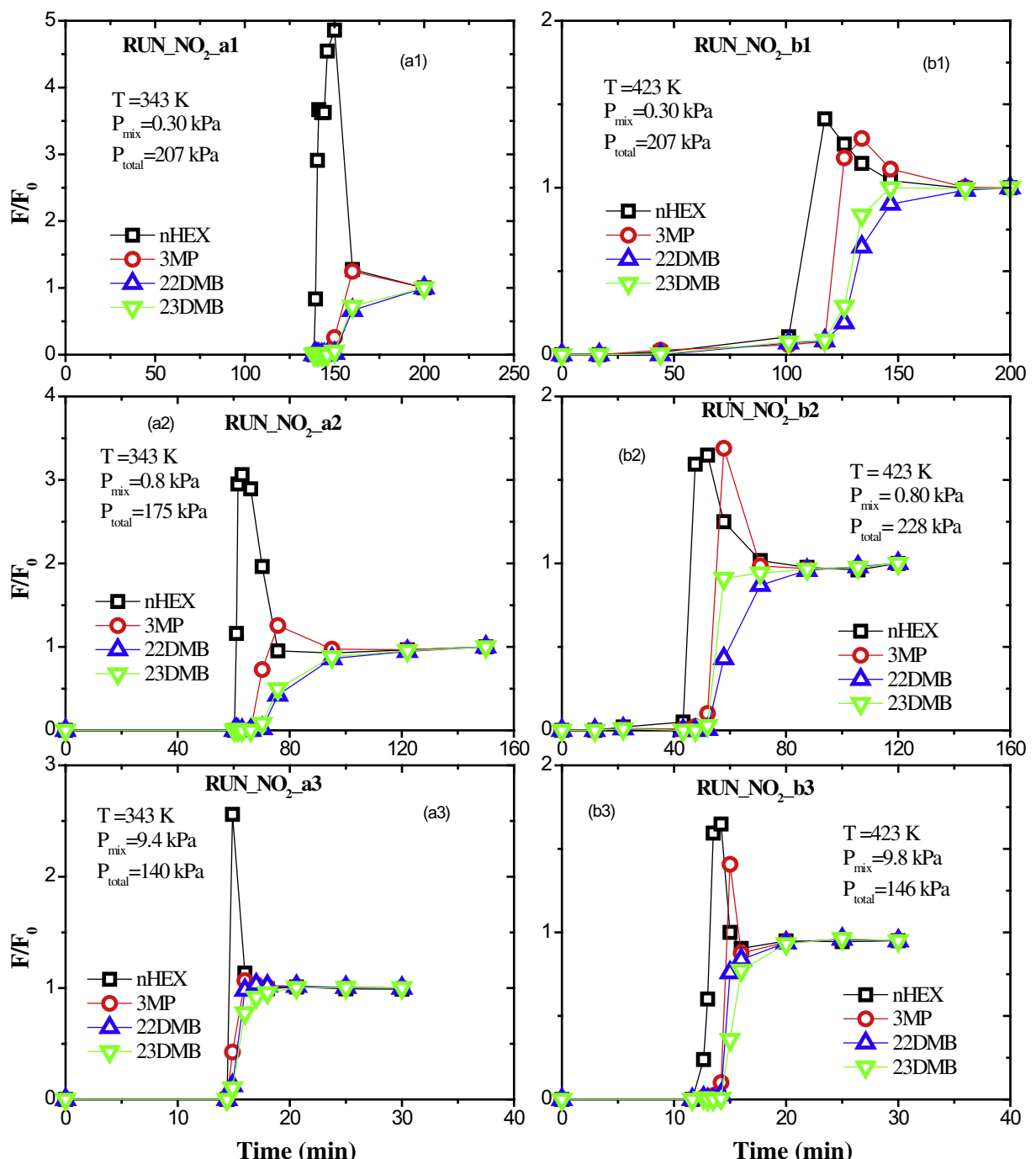

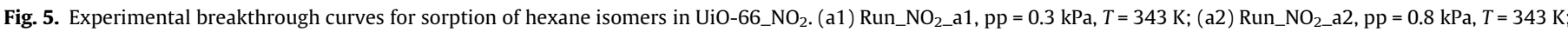

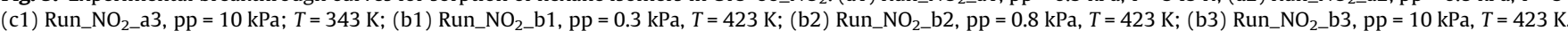

Table 5

Experimental conditions and amounts adsorbed of the hexane isomers in MOF UiO-66_NH $\mathrm{NH}_{2}$.

\begin{tabular}{|c|c|c|c|c|c|c|c|c|c|}
\hline \multirow[t]{2}{*}{ Run } & \multirow[t]{2}{*}{$T(\mathrm{~K})$} & \multirow[t]{2}{*}{ Helium flow rate $(\mathrm{mL} / \mathrm{min})$} & \multirow[t]{2}{*}{ Mixture pressure (kPa) } & \multirow[t]{2}{*}{$m_{\mathrm{MOF}}(\mathrm{mg})$} & \multicolumn{4}{|c|}{ Partial loading (g/100 gads) } & \multirow[t]{2}{*}{ Total loading (g/100 gads) } \\
\hline & & & & & 22DMB & 23DMB & $3 \mathrm{MP}$ & $n$ HEX & \\
\hline $\mathrm{NH}_{2 \_} \mathrm{a} 1$ & 343 & 35 & 0.3 & 452 & 1.6 & 1.9 & 1.8 & 1.7 & 4.9 \\
\hline $\mathrm{NH}_{2 \_} \mathrm{b} 1$ & 423 & & & & 1.0 & 1.0 & 0.9 & 0.8 & 3.7 \\
\hline $\mathrm{NH}_{2 \_} \mathrm{a} 2$ & 343 & 20 & 6 & & 2.0 & 3.2 & 3.4 & 3.4 & 12.0 \\
\hline $\mathrm{NH}_{2}$ b2 & 423 & & & & 1.2 & 1.4 & 1.0 & 0.8 & 4.4 \\
\hline
\end{tabular}

Table 6

Selectivities of hexane isomers in UiO-66_ $\mathrm{NH}_{2}$.

\begin{tabular}{|c|c|c|c|c|c|}
\hline \multirow[t]{2}{*}{ Run } & \multirow[t]{2}{*}{$T(\mathrm{~K})$} & \multirow[t]{2}{*}{ Mixture pressure (kPa) } & \multicolumn{3}{|l|}{ Selectivity's } \\
\hline & & & 22DMB/nHEX & 23DMB/nHEX & $3 \mathrm{MP} / n \mathrm{HEX}$ \\
\hline $\mathrm{NH}_{2 \_\mathrm{a} 1}$ & 343 & 0.3 & 0.9 & 1.1 & 1.1 \\
\hline $\mathrm{NH}_{2}$ b 1 & 423 & & 1.2 & 1.2 & 1.1 \\
\hline $\mathrm{NH}_{2 \_} \mathrm{a} 2$ & 343 & 6 & 0.6 & 0.9 & 1.0 \\
\hline $\mathrm{NH}_{2 \_} \mathrm{b} 2$ & 423 & & 1.5 & 1.8 & 1.3 \\
\hline
\end{tabular}

\subsection{Comparison of selectivities in the functionalized UiO-66 solids}

Fig. 7a and $\mathrm{b}$ shows the effect of total mixture loading upon the selectivity between $22 \mathrm{DMB} / n \mathrm{HEX}$ and $22 \mathrm{DMB} / 3 \mathrm{MP}$ in the three functionalized UiO-66 solids, with the purpose to an easier understanding of the influence of the sorption uptake on the hexane isomers separation. It is also show for a comparison the results obtained in the bared UIO-66 studied previously [14]. 

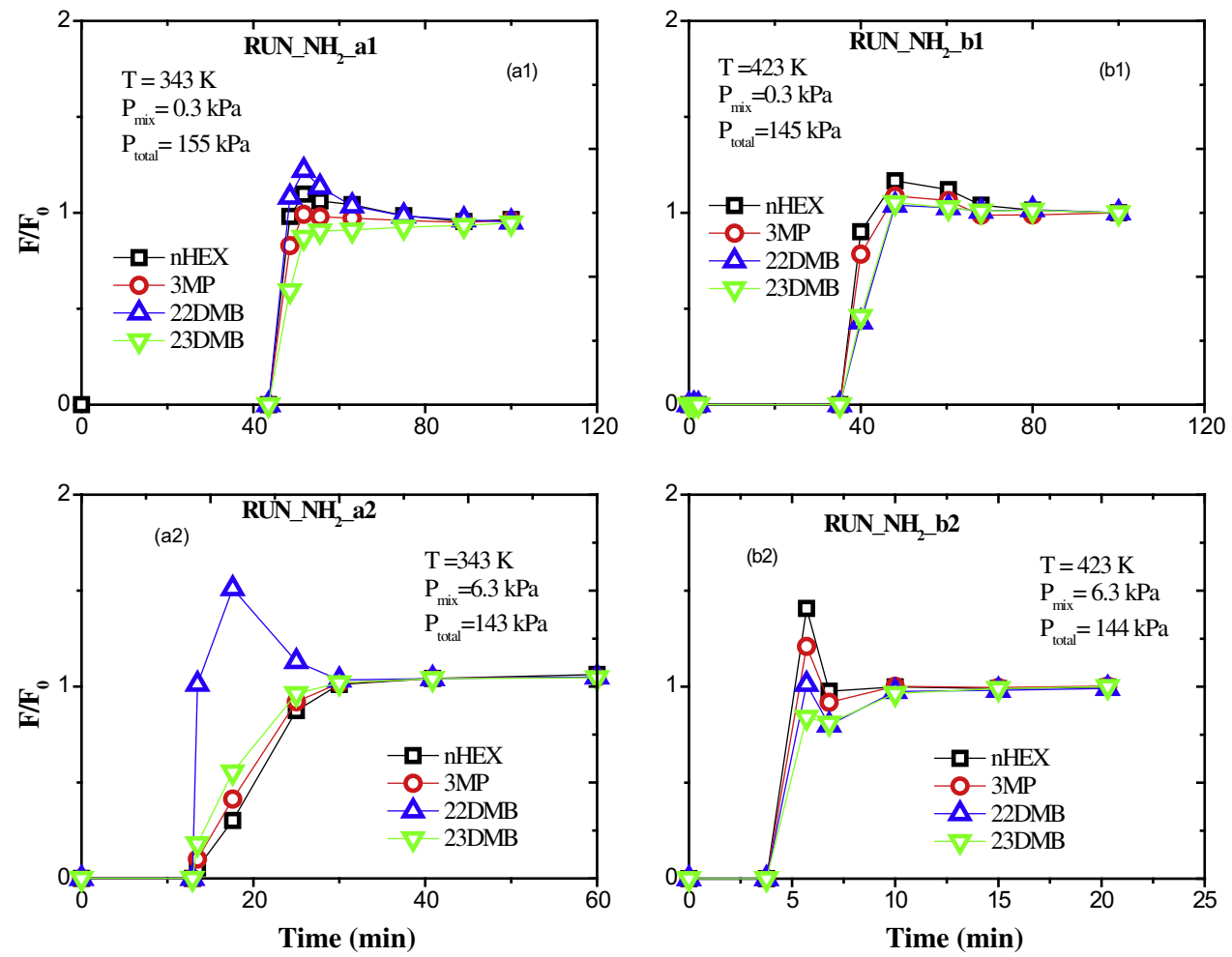

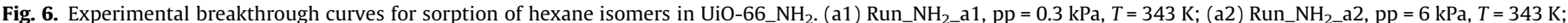
(b1) Run_NH $\mathrm{NH}_{2}$ b1, pp $=0.3 \mathrm{kPa} ; \mathrm{T}=423 \mathrm{~K}$; (b2) Run_NH 2_b2, pp $=6 \mathrm{kPa}, T=423 \mathrm{~K}$.

Regarding the UiO-66_Br solid (Fig. 7a), lower uptakes favor the separation between 22DMB and $n$ HEX with a selectivity close to three. For higher uptakes the selectivity values decline to reach a plateau with a value nearly to 1.3 . The $3 \mathrm{MP} / 22 \mathrm{DMB}$ selectivity (Fig. 7b) is very small and constant (between 1.0 and 1.1). Concerning the UiO-66_NO $\mathrm{NO}_{2}, 22 \mathrm{DMB} / \mathrm{nHEX}$ selectivity is between 1.5 and 1.8 (Fig. 7a), but the major difference relatively to the UiO-66_Br is found at low uptake where the selectivity 3MP/ 22DMB (Fig. 6b) is the highest, reaching the value of 1.3. Finally, in the case of the UiO-66_NH $\mathrm{NH}_{2}$ when uptake increases leads to a value of 0.6 for both $22 \mathrm{DMB} / n \mathrm{HEX}$ and $22 \mathrm{DMB} / 3 \mathrm{MP}$ ratios (Fig. $7 \mathrm{a}$ and $b)$.

In a general overview of Fig. 7a and b, selectivity seems to decrease when the total adsorbed amount increases. A possible explanation for this behavior comes from the fact that UiO-66 solid exhibits entropy effects due to rotational limitations [14] of linear molecules in the smaller tetrahedral cages (leading to their exclusion), which seems to be responsible for the observed reverse shape selectivity. At low loadings, selectivity is higher between branched and linear paraffins since branched molecules can access to both tetrahedral and octahedral cages. Thermodynamically, smaller tetrahedral cages will be first filled and then the octahedral ones. Accordingly, at high partial pressures (high loadings), only the octahedral cages continue adsorbing molecules. However, in this case linear molecules are preferably adsorbed over branched ones (conventional effect) due to the higher Henrýs constants. Therefore, this results in a decrease of the branched/linear sorption selectivity, suggesting also the presence of two different sorption mechanisms: an equilibrium driven at low loadings and a kinetic control at high loadings.

In a global comparison between bared UIO-66 and functionalized we can conclude that the selectivity's as a function of the total amount adsorbed do not change significantly in the functionalized samples except for the case of UiO-66_ $\mathrm{NH}_{2}$ where a selectivity reversal for $22 \mathrm{DMB}$ is observed at high loadings.

\section{Conclusions}

UiO-66(Zr) functionalized MOFs bearing $\mathrm{Br}, \mathrm{NH}_{2}$ or $\mathrm{NO}_{2}$ groups have been successfully synthesized at the multi-gram scale using an atmospheric pressure route with the final aim of investigating the influence of this functionalization on their adsorptive properties, specifically on the hexane isomer separation.

Several breakthrough screening studies have been performed on the UiO-66_Br, _ $\mathrm{NH}_{2}$ and _ $\mathrm{NO}_{2}$ at different temperatures and partial pressures. Thus, UiO-66_Br shows a reverse shape selectivity, previously observed for the bared UiO-66 [14], with a $22 \mathrm{DM}>23 \mathrm{DMB}>3 \mathrm{MP} \gg n \mathrm{HEX}$ order, with a total adsorbed amount reaching $15 \%$. Although the best selectivity between $22 \mathrm{DMB}$ and $n$ HEX in UiO-66_Br is found at low uptake with a value of 3, this material seems to be only suitable for separating $n \mathrm{HEX}$ from the other isomers. Similarly, the uptake obtained with the UiO$66 \_\mathrm{NO}_{2}$ reaches $15 \%$ with an analogous sorption hierarchy. However, unlike UiO-66_Br, UiO-66_ $\mathrm{NO}_{2}$ exhibits a certain degree of selectivity between $3 \mathrm{MP}$ and the di-branched isomers at low uptake (1.3).

Finally, the UiO-66_NH $\mathrm{NH}_{2}$ exhibits a different sorption behavior than that of their $\mathrm{Br}$ or $\mathrm{NO}_{2}$ analogues. The adsorbed amount decreases to values lower than $12 \%$, suggesting that amino groups partially block the accessibility of the tetrahedral cages to all the isomers. Although at low uptake the selectivity is very small, the sorption hierarchy changes when uptake increases $(n \mathrm{HEX}>3 \mathrm{MP} \gg 23 \mathrm{DMB}>22 \mathrm{DMB})$ with an inversion in selectivity for both $22 \mathrm{DMB} / n \mathrm{HEX}$ and $22 \mathrm{DMB} / 3 \mathrm{MP}$ ratios reaching a value of 0.6. Interestingly, UiO-66_NH ${ }_{2}$ satisfies the criteria for upgrading TIP processes since high RON di-branched paraffins exhibit a 

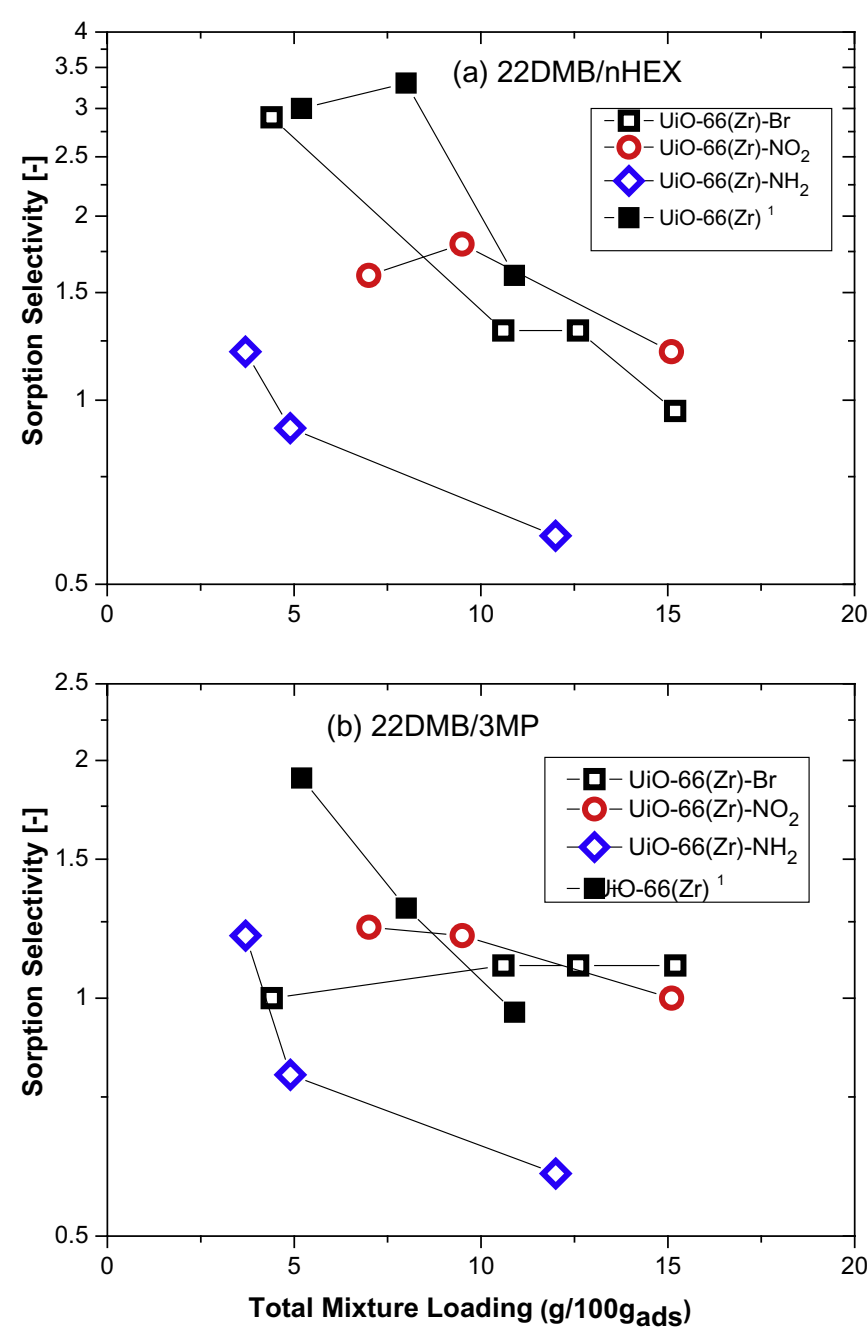

Fig. 7. Sorption selectivity as a function of total mixture loading for the functionalized MOFs and bared samples. (a) Between 22DMB and $n$ HEX; and (b) between 22DMB and 3MP. ${ }^{1}$ Data from reference [14].

significant selectivity relatively to the low RON parents (monobranched and linear ones) at high uptake.

\section{Acknowledgments}

The research leading to these results has received funding from the European Community's Seventh Framework Programme (FP7/ 2007-2013) under grant agreement no. 228862 and the FrancoPortuguese PAUILF program 2008-2011.

We also acknowledge the helpful comments of the reviewers that help us to improve significantly our paper.

\section{Appendix A. Supplementary data}

Supplementary data associated with this article can be found, in the online version, at http://dx.doi.org/10.1016/j.micromeso.2012. 12.017 .

\section{References}

[1] See theme issues: Metal-organic frameworks, Chem. Soc. Rev. 1201 (2010) 112, Chem. Rev. (2012) 673-1268.

[2] M. Kim, S.M. Cohen, CrystEngComm (2012), http://dx.doi.org/10.1039/ c2ce06491j.

[3] H. Deng, C.J. Doonan, H. Furukawa, R.B. Ferreira, J. Towne, C.B. Knobler, B. Wang, O.M. Yaghi, Science 327 (2010) 846-850.

[4] M. Kandiah, M.H. Nilsen, S. Usselgio, S. Jakobsen, U. Olsbye, M. Tiset, C. Laraby, E.A. Quadrelli, F. Bonino, K.P. Lillerud, Chem. Mater. 22 (2010) 6632-6640.

[5] S. Horike, S. Bureekaew, S. Kitagawa, Chem. Commun. (2008) 471-473.

[6] G. Férey, C. Serre, T. Devic, G. Maurin, H. Jobic, P.L. Llewellin, G. Weireld, A Vimont, M. Daturi, J.S. Chang, Chem. Soc. Rev. 40 (2011) 550-562.

[7] N. Ramsahhye, T.K. Trung, S. Bourrelly, Q. Yang, T. Devic, G. Maurin, P. Horcajada, P.L. Lllewellyn, P. Yot, C. Serre, Y. Filinchuk, F. Fajula, G. Férey, P. Trens, J. Am. Chem. Soc. (2011). http://dx.doi.org/ja-2011-03042b.

[8] P.S. Crespo, E.V.R. Fernandez, J. Gascon, F. Kapteijn, Chem. Mater. 23 (2011) 2565-2572.

[9] C. Gaudin, D. Cunha, E. Ivanoff, P. Horcajada, C. Chevé, A. Yasri, O. Loget, C. Serre, G. Maurin, Micropor. Mesopor. Mater. 157 (2012) 124-130.

[10] T.C. Holcombe, Isomerization process, US Patent 4, 210, 771, 1980.

[11] P.S. Bárcia, J.A.C. Silva, A.E. Rodrigues, Energy Fuels 24 (2010) 1931-1940.

[12] P.S. Bárcia, J.A.C. Silva, A.E. Rodrigues, Energy Fuels 24 (2010) 5116-5130.

[13] J.H. Cavka, S. Jakobsen, U. Olsbye, N. Guillou, C. Lamberti, S. Bordiga, K.P. Lillerud, J. Am. Chem. Soc. 130 (2008) 13850-13851.

[14] P.S. Bárcia, D. Guimarães, P.A.P. Mendes, J.A.C. Silva, V. Guillerm, H. Chevreau, C. Serre, A.E. Rodrigues, Micropor. Mesopor. Mater. 139 (2011) 67-73.

[15] Q. Yang, A. Wiersum, P. Llewellyn, V. Guillerm, C. Serre, G. Maurin, Chem. Commun. 47 (2011) 9603.

[16] S.D. Vinot, G. Maurin, C. Serre, P. Horcajada, D.P. Cunha, V. Guillerm, E.S. Costa F. Taulelle, C. Martineau, Chem. Mater. 24 (2012) 2168-2177.

[17] P.S. Bárcia, J.A.C. Silva, A.E. Rodrigues, AIChE J. 53 (2007) 1970-1981.

[18] S.J. Garibay, S.M. Cohen, Chem. Commun. 46 (2010) 7700-7702.

[19] S. Couck, E. Gobechiya, C.E.A. Kirschhock, P.S. Crespo, J.J. Alcañiz, A.M. Joaristi, E. Stavitski, J. Gascon, F. Kapteijn, G.V. Baron, J.F.M. Denayer, ChemSusChem 4 (2012) 740-750. 